\title{
Sustainable development and harmonization of the architectural environment of cities
}

\author{
Nadiia Shebek ${ }^{1, *}$, Viktor Timokhin ${ }^{2}$, Yuliia Tretiak $^{3}$, Ievgenii Kolmakov ${ }^{1}$, and Oleksandr Olkhovets ${ }^{4}$ \\ ${ }^{1}$ Kyiv National University of Construction and Architecture, Department of Town Planning, Kyiv, Ukraine \\ ${ }^{2}$ Kyiv National University of Construction and Architecture, Department of Architectural Environment Design, Kyiv, Ukraine \\ ${ }^{3}$ Kyiv National University of Construction and Architecture, Department of Drawing and Painting, Kyiv, Ukraine \\ ${ }^{4}$ Kyiv National University of Construction and Architecture, Department of Information Technology in Architecture, Kyiv, Ukraine
}

\begin{abstract}
The article emphasized the necessity of preserving spiritual values in the process of sustainable development of cities and urban communities. The article considered harmonization of the architectural environment as the ultimate goal and the defining condition for sustainable development of settlements. Basing on the principles of urban synergetics proposed to use internal reserves as well as the selforganization potential of the population and urban planning effectively redistributes resources and reserves. The article deals with the main provisions of the architectural environment harmonization theory with the consideration of different ideas of harmony, the importance of achieving correspondence between a person's world-view and his surroundings, the expediency of taking into account interpersonal interactions between members of society. The strategic directions of penitentiary environment improvement at all organizational levels outlined. It proposed to form multi-level public spaces for recreation and communication of residents in the centers of historical cities where there is not enough free space. The ways to use recycled materials products for the buildings and structures construction, urban areas improvement, equipment manufacturing were been outlined.
\end{abstract}

\section{Introduction}

The UN conferences on the future of humankind recognized problems of sustainable development of cities and urbanized territories, the humanization of the man artificial environment in a too pragmatic era of total globalization as major issues (Stockholm, 1972; Istanbul, 1996; Johannesburg, 2002; Rio de Janeiro, 1992, 2002, 2012 , etc.). However, in addition to the material component of this environment, one should pay attention to the spiritual values of urban culture, since society recognizes "cities and towns as centers of civilization, generating economic development and social, cultural, spiritual and scientifical advancement" [1, item 2].

Among these values, the special emphasis placed on the desire to reconcile the existing "chaos" of entirely urbanized territories and the "cosmos" of historic cities to harmonize the architectural and urban environment at all levels and stages of its integrated development. This development must be focus not only on the economical and the efficient use of resources but mainly on the maximum using of internal reserves and urban development potentials as well as urban residents' activities. This activity ultimately contributes to the integration and harmonicity of sustainable development. It is the harmonization, as the protection and reconciliation of the material and spiritual goals and values of the urban communities in the self-organization processes, that, in the end, reveals the potential and the hidden internal reserve of sustainable development.

\section{Formulation of the problem}

The key to achieving the global Sustainable Development Goals is the harmonization of national strategies of economic growth, social integration, and environmental protection [2]. Ukraine's progress in these strategic directions significantly complicates by the painful problems of Ukrainian society. There are include the low efficiency of available material and intangible resources use; lack of efforts to strengthen ties between members of the society; low level of tolerance towards those who are on the sidelines of social life; lack of attention from both the authorities and the citizens to the maintenance of environmental balance in urban areas.

Experts in different fields of knowledge are searching for ways to overcome these and other obstacles for a prosperous future. For example, Ukrainian architects see the following perspectives:

- Achieving consistency between the evolution of urban systems and the synergistic principles of harmonical development.

- Consideration of socio-psychological characteristics of the population different categories in the organization of the architectural environment of settlements.

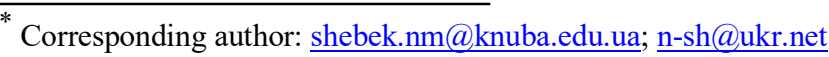


- The penitentiary environment improvement at all levels from the territorial network to the arrangement of the separate premises of establishments.

- Creating optimal conditions for various forms of leisure, recreation, communication between residents in the city areas that lack space for this purpose.

- Cardinal change in citizens' attitudes towards waste recycling and the introduction of advanced resource reuse technologies.

\section{Ways to enhance the architectural environment sustainability in cities}

\subsection{Self-organization and sustainable development of the urban environment}

Recently, the problem of finding and identifying untapped potentials and reserves of urbanization has attracted the attention of many professionals and international organizations seeking cooperation. The UN documents suggest “... enhancing inclusive and sustainable urbanization and capacity for participatory, integrated and sustainable human settlement planning and management in all countries" [2, item 11.3] by 2030. In $20^{\text {th }}$ century modern architecture and urban planning, the problem of harmonization, as an important factor and potential for integrated development of the environment, has received impetus for a solution, starting with F. L. Wright's research utopian projects. In his work, the eminent architect focused on the fact that “... modern homes and cities ... must have the kind of harmony that any well-balanced mechanism has, but such harmony, however advanced it might be at the moment, is, above all, only the foundation of beauty - the promise of its possibility" [3, p. 72]. Many other architects Le Corbusier, L. Mies van der Rohe, A. Aalto, E. Saarinen - were involved in these studies and discussions, extending and deepening the concept of harmony from the point of view of the proportion of the environment, enhancing its social, ecological, aesthetic and other humanistic values and qualities.

At the turn of $20^{\text {th }}$ and $21^{\text {st }}$ centuries, architects and urban planners in science and practice have increasingly paid attention to the problems of the urban environment harmonization at all levels of its development planetary and state, regional and local. It is enough to mention the Ekistics and the concept of the Eikumenopolis - K. Doxyadis's planetary city. The quintessence of this theory was the creation of a global urban environment of "universal happiness" for all people on the planet without exclusions [4]. K. Lynch, who believed that the aesthetic qualities of the city and region environment were the leading ones, added to these humanistic demands: “... undoubtedly, we need an environment not only satisfactorily organized, but also with symbolic color and poetic content. It should speak about the individual and about society as a whole, about historical traditions and dreams about the future, about the natural environment and about the complex functional nature of cities" [5, p. 112].
In some studies, the ideas of harmonizing the planning structure of the city implemented with the help of harmonic rows of the golden section [6]. This unique proportional system, which focuses on the maximum economy and conservation of resources in the creation of objects of living and inanimate nature, as well as in the aesthetic perception of the architectural environment, has been fully utilized in yet another direction of urban planning theory - in urban synergetic [7]. The analysis of the self-organization of the urban population showed that the processes of cities' sustainable development accompanied by the redistribution of the volumes of transport and pedestrian work of the population in accordance with harmonic rows of the golden section. This has allowed harnessing the self-organization potential of the population and urban planning at some stages of the city's development as well as directing this internal reserve and resource savings to harmonize sustainable development.

The harmonization, as any process of natural development, based on its undulating nature with "downturns" and "ascents" of urban activity and activity of urban residents. This creates the preconditions for the accumulation and saving of internal resources in some periods so that at other stages of urban development, they can spent as efficiently as possible to maintain its sustainability. The range of sustainable development includes ultra-short waves of transformations of the architectural environment, short waves of changes in modes of urban development, medium waves of historical city development, and long waves of evolution. The one-generation life of residents identify as the primary parameter humanizing the city's sustainable development. At the same time, the community of urban dwellers divided into four communities - townsfolk, settlers, urban people and colonists - who perceive the space-time of the city in different ways, and, accordingly, have the opportunity to form the most suitable for themselves environment.

In the area of urban synergetic, a system of genre design proposed to harmonize these environments. In a self-organizing and participatory movement, in which specific urban communities work closely with urban planners, designers, and managers, there is an opportunity to create a fully-fledged and harmonious urban environment at every stage of sustainable development, with broad involvement of its potentials, including artistic and aesthetic. In the genre of architectural topic, the community of townsfolk, for whom the past is most important, finds a complete set of means of harmonization to reproduce the historical traditions of urban culture. The genre of architectural rhetoric that helps artistically respond to the current challenges of today is best suited to the settlers, who prefer to solve today's problems. Urban people, with the priority of the future, focus on the architectural topic, which allows one to look into the near future with the help of artistic images and symbols similar to literary tropes (metonymy, metaphor, etc.). For colonists, with their uncertainty about the passage of time, it is important to find new utopian images and symbols of the distant future that contribute to the prediction and 
forecasting of paths for further sustainable development. That is why architectural poetics will suit their preferences.

From the standpoint of urban synergetic, the future of urban development unconditionally linked to the use of internal reserves and potentials of self-organization processes, the naturalness of which is closely linking to their fluctuating nature and the effective redistribution of resources and reserves, including artistic and aesthetic, at all stages.

The use of all the reserves and potentials of sustainable development is a leading factor in the study of effective methods and means of harmonizing the architectural environment at all levels of the current city organization.

\subsection{Architectural environment and sustainable development of urban communities}

Maintaining harmony between people and the environment is a major outcome of the global sustainable development strategy. The lack of unanimity in the interpretation of harmony, narrow profile consideration of the architectural environment, as well as the widespread shift of focus from person to society or to a separate part of it significantly, complicate the realization of this intention.

The architectural environment is the object of study, which allows seeing all aspects of the city in their syncretic unity, and tracing the peculiarities of its transformation in interaction with the person in its individual, collective and social manifestations. Recognition of the right to life and self-realization for each person in the best possible conditions are forces to refrain from rigidly defining the parameters of a harmonious environment and encourages the search for mechanisms of mutually harmonious transformation of diverse environmental entities. These principles are bases of the architectural environment harmonization theory. The causes and consequences of actions aimed at improving the environment, which forms and continuously changes as the result of the natural interpenetration anthropogenic, social, and psychological surroundings in the course of their historical development, investigate within this section of architectural theory.

As a result of drawing parallels between the properties of the artificial environment and the ways of thinking of populations' different categories, which were systematized in Socionics [8], sixteen types of architectural environment were distinguished, each of which is presented as an ideal model of living environment for a representative of one of sixteen possible types of energy-information metabolism. The fundamental differences between different types of environmental entities are determining by a unique combination of eight morphological, phenomenological, semantic, and praxeological features that describe their intrinsic and external properties.

The criterion of the architectural environment harmoniousness of each type is the value priority inherent in the carriers of the corresponding kind of energy-information metabolism. The architectural environment harmoniousness criterion of each type is characterizing by a system among eight material, social, humanitarian, and organizational values, indicated in the sequence of reduction of their importance. Each criterion is defining by qualitative and, in some cases, quantitative indicators. As a result, sixteen, fundamentally different descriptions of the perfect environment are forming that characterize the widest possible range of harmony conceptions inherent in persons who have received different ego-orientations, and different sets of psychic functions from birth, according to C. G. Jung's terminology.

From the carriers' point of view of a certain type of energy-information metabolism, the architectural environment looks as a typologically homogeneous void structure with interconnected "mastered" sites. Fragments of urban territory that do not fall within the sphere of vital interests of those persons category form cavities of this structure. From the point of society view, the architectural environment of the city is a megastructure of sixteen interpenetrating typologically homogeneous layers. Within this megastructure, the "mastered" fragments of each layer put in the voids of all other structures. As a result, in those areas of cities, where the process of forming an architectural environment acquires signs of completeness, environmental systems are forming - combinations of those types of architectural environment that correspond to the value priorities of the members of the respective Dyads, Cuadras, and Octaves, which have been described by Socionics. In this way, favorable conditions created in the urban environment for the territorialspatial grouping of persons whose social integration is the most productive. With that, fragments of the architectural environment that may interest members of the society, who difficult to find common ground, are physically distant from one another.

The ideal tracery, which would result from the combination of the architectural environment theoretical models, had been comparisoned with the characteristics of real surroundings, which formed at various European cities for quite some time. This comparison showed the ability of the proposed methodology accurately to describe the mechanisms of the natural development of the settlements' architectural environment. Therefore, we can recommend it as an effective means of them harmonization. Application of the proposed methodology application allows identifying sustainable tendencies of environmental systems and environmental networks organization, corresponding to effective forms of interaction between single residents and between individual communities, which have historically formed in different parts of the city. Purposeful support for these trends in the project proposals for the inevitable modernization of settlements will be the key to the harmonious development of the cities' architectural environment and sustainable development of urban communities. 


\subsection{Sustainable development and architecture of penitentiary facilities}

Sustainable urban and community development goals include the provision of universal access to adequate safe and affordable housing and essential services [2]. This requirement also applies to those members of society who deprived of their liberty for one or other reasons.

The concepts of the ideal penitentiary, which is certainly a part of the social, urban and cultural (subcultural) system of the world, known since ancient times, can only be mentioned by Panopticon of Bentham - the "seeing eye" of law and order, the Pennsylvania and progressive 18-19 century, criticism of the modern prison system M. Foucault, etc. Another thing is that the aestheticization of the architectural environment of the correctional system in the context of its improvement and progressive development has hardly attracted the attention of researchers and practitioners until recently. Considering the correctional system from the standpoint of realization of the ideas of the urban environment synergism and harmonization, of which penitentiary complexes are part, we can argue that, to paraphrase F. L. Wright's words, the sign of harmony is inherent for any well-balanced system. However, today, to imagine a prison system that is perfectly balanced, integrated into the urban environment, and therefore harmonious and beautiful in all respects, is quite difficult.

Problems of formation of innovative penitentiary institution, which would combine elements of new and historically traditional in its system, search for variants of harmonious relations between elements of economy, ecology, humanity, and beauty, which is a sign of the system's stability, expressed in search and experimental projects of correctional complexes, history as it is today. Examples of the desire for the aesthetic perfection of the penitentiary environment, which is an integral part of the modern city, can serve almost all the basic prototype models of prisons and correctional buildings, which revealed attempts to combine penitentiary technology of correction and supervision, functional search for aesthetic and artistic relevance emotional orientation of architectural forms. Such attempts at harmonization include the New Gates Prison in London (1770-1785), the Panopticon of J. Bentham (1791), the Philadelphia Prison in Cherry Hill (1825), and the Pentonville Prison in London (1842)) Arnhem Prison in the Netherlands (1884, reconstructed in 1992), and their "followers" correctional institutions of the "new generation" of the mid-late twentieth and early twentieth centuries.

The principles of improving the penitentiary environment should work at all levels of its system organization and cover the spatial-temporal, functional, structural, planning, and compositional aspects of the harmonization process. Functional harmonization of the penitentiary system ensures optimal flow of the life process, which expressed in accordance with the rhythms and regimes, in the sequence of processes, and corresponding harmonization measures. An example of such relevance and orderliness are the latest-generation "cluster" correctional institutions, in which isolation and combinations of different groups of people and activities occur rhythmically and organically inappropriate spaces, which can act as part of a single mechanism, both as an autonomous and self-sufficient its subdivision [9] (Fig. 1).

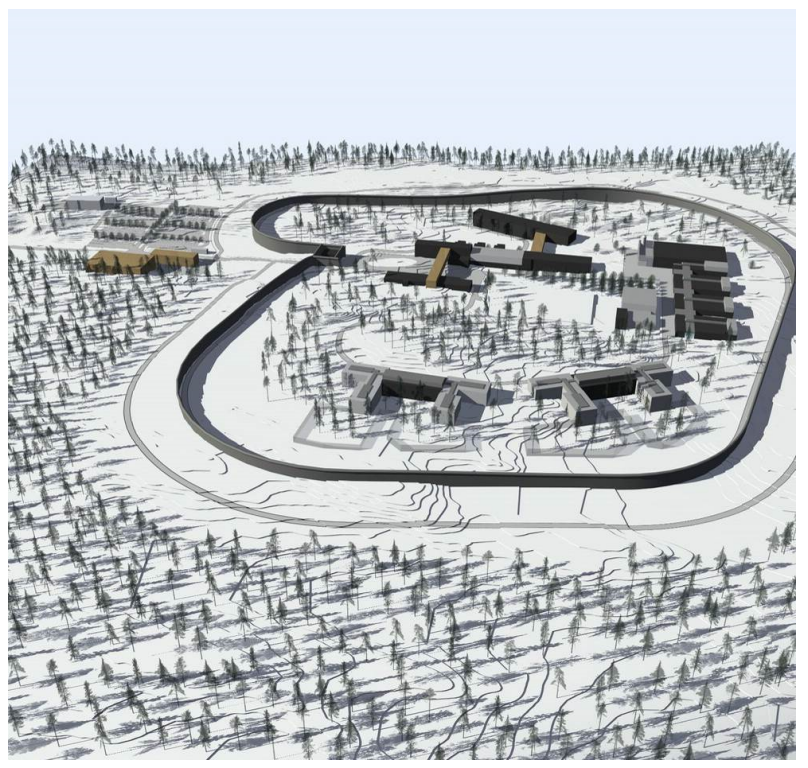

Fig. 1. Halden Correctional Facility, Norway, 2010, https://prisondesign.wordpress.com/2011/05/10/chris-alker-onthe-architecture-of-re-socialization/

The diversity of approaches to the placement of penitentiary complexes in the structure of the city is because environmental actors are not only sentenced and official staff but also residents and visitors. For this reason, at the urban level, the environment of correctional complexes works mainly emotional and psychological indicators that characterize the perception of the penitentiary complex from the outside environment. The harmonious placement of penitentiary complexes in the city implies interactivity between the penitentiary and urban environment in terms of, first, the effectiveness of the penitentiary complex as an element of the social services system, and second, its representativeness, that is, the representative architecture. This approach is in line with the guidelines outlined in the latest guidance documents for achieving sustainable urban development through investment in infrastructure and urban design for climate change and improvement, as well as enhancing social inclusion and accessibility of services for all residents, regardless of age or status, by condition for adherence to the principles of universal design [10].

An important feature of the aesthetic perception of the general appearance of the security institution is the expressiveness and imagery of the silhouette of the complex. Due to the high fence, the perception of the complexes from the far plans made realized by increasing the number of floors in some buildings or by arranging a panoramic view of the architectural ensemble from high points of the landscape, which does not meet the requirements of the regime. Therefore, it is advisable not to increase the number of buildings stories, but to give importance to the architectural and artistic design of the fence and main entrance, similar to the 
correctional facility in Bastoey, Norway (Fig. 2), Florida State Correctional Institute in Marianna, US, and more [11]. Techniques for forming a distinctive compositional connection of buildings and structures with the environment - landscape or urban development contribute to the inclusion of such institutions in the existing system of architectural and urban development, increase the socio-psychological "transparency" of the correctional system and improve the interrelationship.

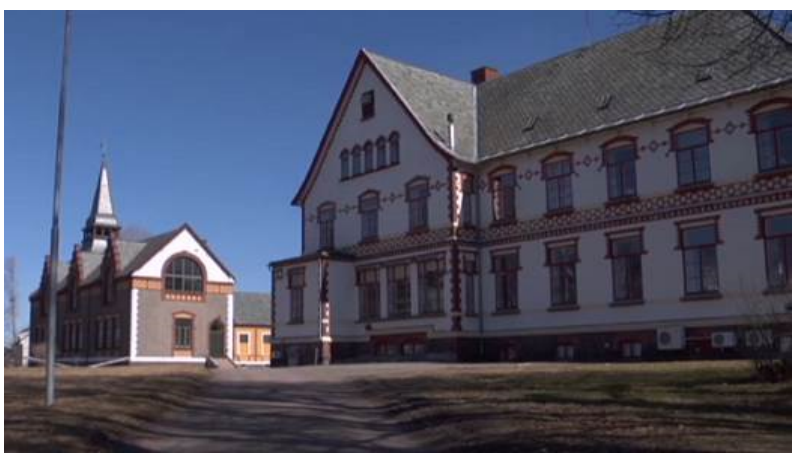

Fig. 2. Correctional Facility in Bastoey, Norway,

https://www.gettyimages.com/photos/bastøy-island

Equally important is the aesthetics and harmonization of correctional buildings and complexes with the environment is the creation of their visual connection with urban development, which carried out by two compositional means: the continuation of the rhythm of development and the creation of emotional and psychological contrast with the urban environment. The first of these can be illustrated by the architecture of the Maryland Correctional Center in Baltimore, USA, which was reconstructed and opened in 1995 [12] (Fig. 3). The new buildings, whose architectural and artistic features correspond to the rhythm, silhouette, and scale of the surrounding urban development, became a visual extension of the old building. Another technique that contrasts the dominant and background volumes is illustrated by the high-rise metropolitan Chicago Metropolitan Correctional Center, designed by G Weiss in 1975 [13], which rises above the surrounding structure and contrasts with its size, tectonics, and dynamics forms (Fig. 4).

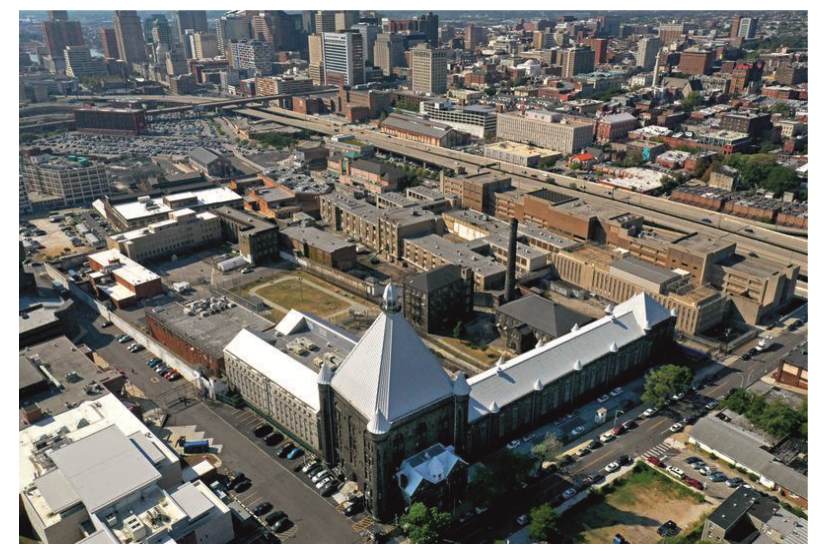

Fig. 3. Maryland Correctional Center in Baltimore, https://www.baltimoresun.com/politics/bs-md-pol-city-jaildemo-20191002-prhkw7odwrepvmb4zkt4uxx7ka-story.html

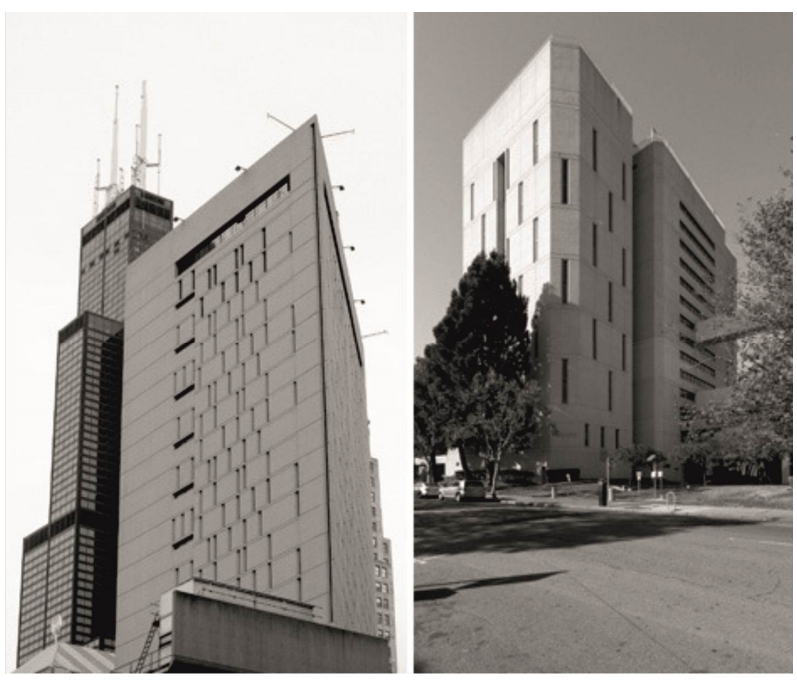

Fig. 4. Metropolitan Correctional Center in Chicago, USA, https://chicagomodern.wordpress.com/2012/03/19/metropolitan -correctional-center/

\subsection{The organization of public spaces in areas with dense historical buildings}

Today, cities are not only centers of economic and social activity, but also powerful communication hubs, places of trade, culture, science concentration, focuses on innovative development, etc. However, in the context of accelerated globalization in congested cities, problems related to the increase of social inequality, lack of adequate housing and developed infrastructure, environmental degradation, irrational use of energy, accumulation of waste, transport overload, and lack of comfortable public spaces are exacerbating. The situation in the central zones of the largest Ukrainian cities indicates the lack of areas intended for communication, recreation, and leisure. The free urban space used only for pedestrian and transport traffic or is not used at all and transformed into an urban wasteland.

Among the challenges of sustainable urban development, considerable attention pay to ensuring universal access to safe, accessible green areas and public places, open for everybody, especially women and children, the elderly and the disabled [2]. One of the alternative solutions to this problem in the context of dense urban development is the formation of open multilevel multifunctional public spaces able to concentrate a large number of comfortable and interesting facilities for leisure, recreation, interpersonal communication in a relatively small area.

As any other place of public life concentration, multilevel public spaces should be accessible and versatile, create conditions for various activity forms, provide visitors' comfort, make impression of hospitable places, include attraction points, promote socialization, have a sufficient degree of isolation from the unfavorable urban environment [14]. We propose making public spaces pedestrian. For this purpose, to create public transport' stops, tiered parking, and cultural facilities at the outer boundaries' nodes of multilevel city structures. 
This scheme designed for use in historic downtown and near particular value architectural complexes. The system of public spaces historically formed in such places gets territorial development through the modernization of certain sections of existing streets, squares, embankments, esplanades, as well as through the development of underground or aboveground levels through the degraded urban landscapes regeneration, in particular industrial facilities. Territorial reserves for the organization of multi-level public spaces also can found in the green areas of cities. Parks and squares, sections of boulevards, and embankments can combine into single spatial systems by arranging additional multi-level links of well-established walking routes.

The live plants that integrated into multi-tiered urban structures, design to organize public spaces [15], will increase the number of green spaces in densely built historic city centers. This path may be one of the most promising means of improving the microclimate in the urban environment.

Creating new urban public multi-level centers in the business, cultural, and shopping regions will help to promote the new technologies introduction, and unique architectural concepts implementation [16]. At the same time, traditional types of urban environments such as a square, a boulevard, a park or a trestle, can get a new interpretation here.

Maintaining the historical architectural ensembles unity and the modern constructions are key importance in the process of reorganizing existing open public spaces or creating new public life centers in multi-tiered urban structures. The constructive system of the objects introduced into the formed urban environment is an important element that influences their threedimensional solution. For the erection of multilevel urban structures, we propose to use beam, beamcantilever, arch, frame, and combined structural schemes. The structural scheme of a multi-tiered urban structure can transform it into a visual dominant for the entire city area [17] (Fig. 5) or facilitate its maximum integration into the existing architectural environment [18] (Fig. 6).

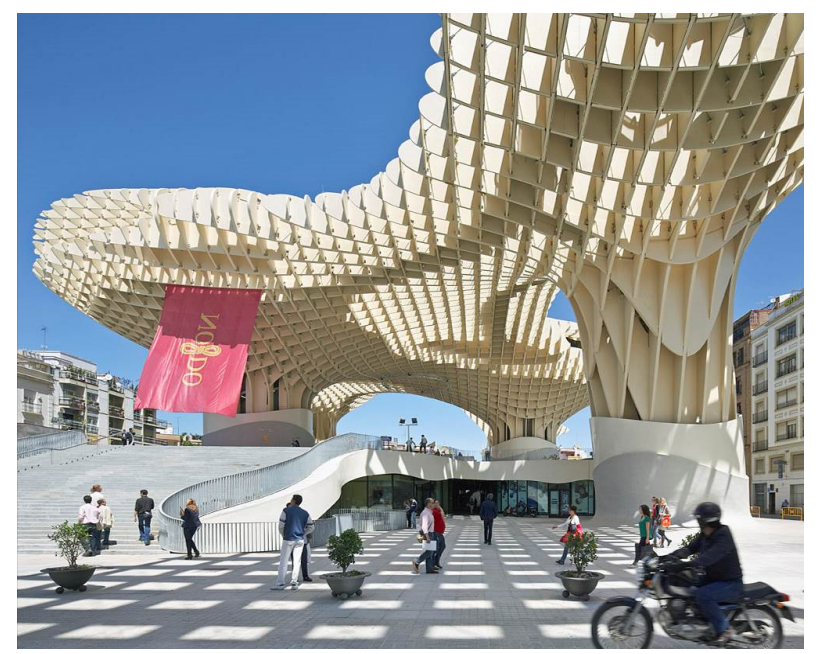

Fig. 5. Metropol Parasol. Seville, Spain, http://www.twofeetoneworld.com/2017-12-two-days-seville/dsc00843/

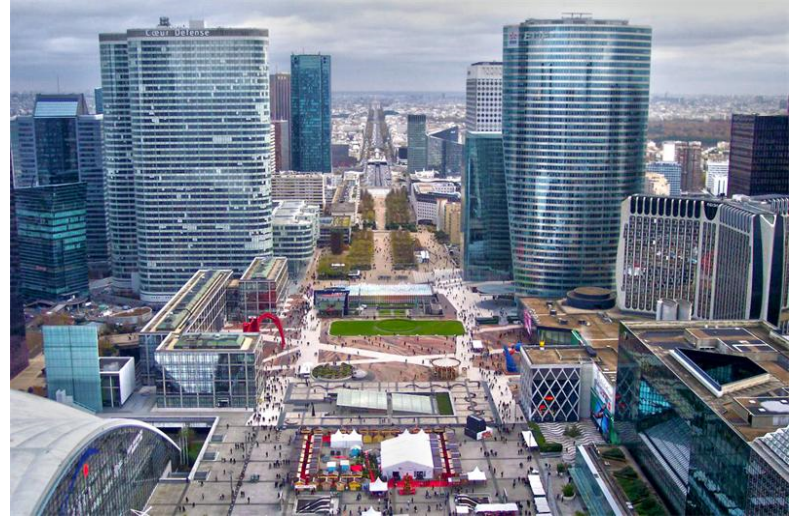

Fig. 6. La Défense Business District. Paris, France, http://grandstroy.blogspot.com/2012/11/grande-arche-de-ladefense.html

New effective materials, including recycled materials, designed to reduce the cost of multi-tiered urban structures, accelerate their erection process, reduce operating costs, and indirectly improve the environmental status of cities as a whole. For example, various products - from insulation materials and exterior facades decoration to individual elements of public spaces [19] (Fig. 7) and urban furniture [20] (Fig. 8) can made from polymer-sand composite materials or recycled plastic.

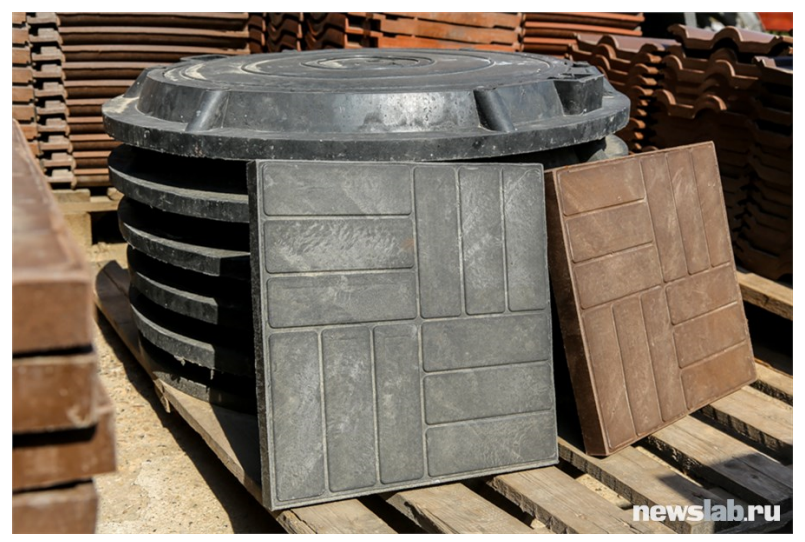

Fig. 7. Pavement tile made of polymer-sand composite, http://newslab.ru/article/719194

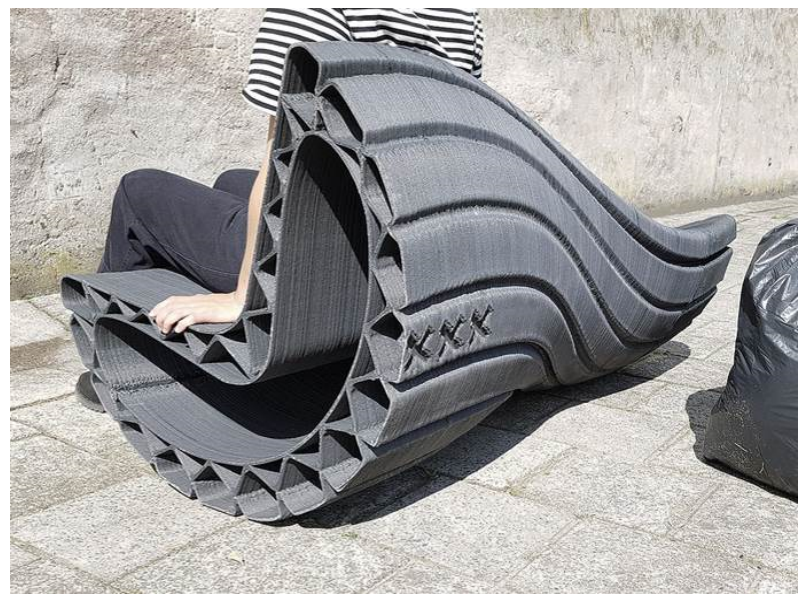

Fig. 8. Recycled plastic bench, Amsterdam, Netherlands, The New Raw, https://thenewraw.org/Print-Your-City-Amsterdam 
The organization of multifunctional multilevel public spaces will facilitate the sustainable development of cities if they will thoughtfully embedded in the existing context. This process requires the development of a long-term action program that, based on the available opportunities analysis, will justify the feasibility of reorganizing the architectural environment as a means of harmonizing the living environment of urban communities and ensuring settlements balanced development.

\subsection{Implementation of advanced resource reuse technologies}

An equally important challenge of modern time is to reduce the negative environmental impact of cities by improving air quality and reducing the amount of waste per resident [2]. The overall state of the environment continues to deteriorate despite the introduction of environmental protection and conservation measures [21]. The concentration degree of harmful substances in the atmosphere exceeds the established norms in some Ukrainian cities [22]. Currently, there are waste recycling enterprises in Ukraine, including plastics, such as "Kyivmiskvtorresources", "Region-2001" and "GALPET", whose products are mainly relatively inexpensive raw materials - granular PET, preforms, PET flakes [23]. Waste collection and sorting are expensive, and the sales revenues are insufficient for further develop production facilities in accordance with current technologies. Due to this and to insufficient support from the state, the garbage processing service at some Ukrainian enterprises as "Region-2001" is pay [24], and some as "Kyivmiskvtorresources" have to stop their activity altogether [25].

Instead, society is interested in changing approaches to waste management. There is a need to develop effective recycling methods to avoid incineration and disposal procedures. The use of secondary raw materials in construction is one such way. A distinctive feature of this method of using recycled materials is its economic benefits since construction products made from recycling expected to be significantly cheaper than similar ones made of prime raw materials.

There are household waste, industrial waste, construction, and repair waste to use in architecture. We chose polymer waste for research, because it pollutes the ocean more than others do, and its processing has great potential. The use in the construction of polymeric recyclables meets the needs of sustainable urban development due to the relatively low cost of energy resources due to the low melting point of plastics. Due to the plasticity of the material and its suitability for painting, construction products based on polymeric recyclables have a high potential for increasing aesthetically attractive architectural and construction products.

Secondary raw materials can act as a constituent of building material or be the only component for the manufacture of construction products. There is some experience with the introduction of both technologies: for example, in India, recycled plastic is using as a filler in concrete instead of sand [26], and in the US, recycled plastics are using as a base material for building blocks [27].

An important disadvantage of existing the production of construction products based on secondary raw materials is its aesthetic and, in a way, psychological unattractiveness. Despite the economic and technical benefits of using such building materials, likely not all potential users will want to transfer their activities to an environment created from recycled waste. Therefore, an important task is to determine the acceptable scope of application of the material based on recycling and to develop solutions designed to improve the aesthetic qualities of such products.

These materials can used in the mass industrial production of prefabricated architectural elements and decoration materials, mainly for non-residential construction. Exactly physicomechanical properties allow used them forbearing and self-bearing structures of low-rise buildings and structures. The recyclable materials have good performance characteristics, low thermal conductivity. They are safe with the addition of flame-retardants, stabilizers, and non-combustible binders such as concrete. Therefore, it is reasonable to use them for the production of bearing structures of any type of buildings and structures or as finishing materials [28, 29] (Fig. 9, 10).

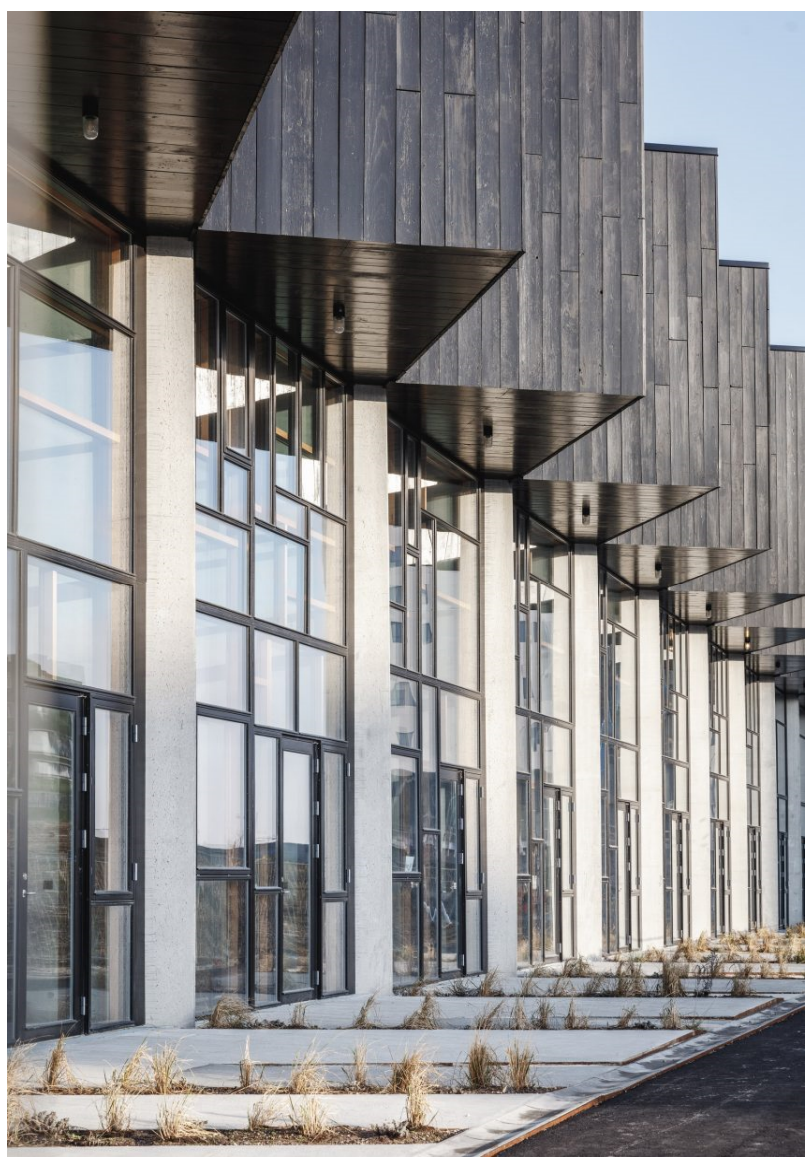

Fig. 9. Residential complex in Copenhagen, Denmark, by Lendager Group, https://www.dezeen.com/2019/04/16/upcycle-studiostownhouses-lendager-group-copenhagen-recycled-materials/ 


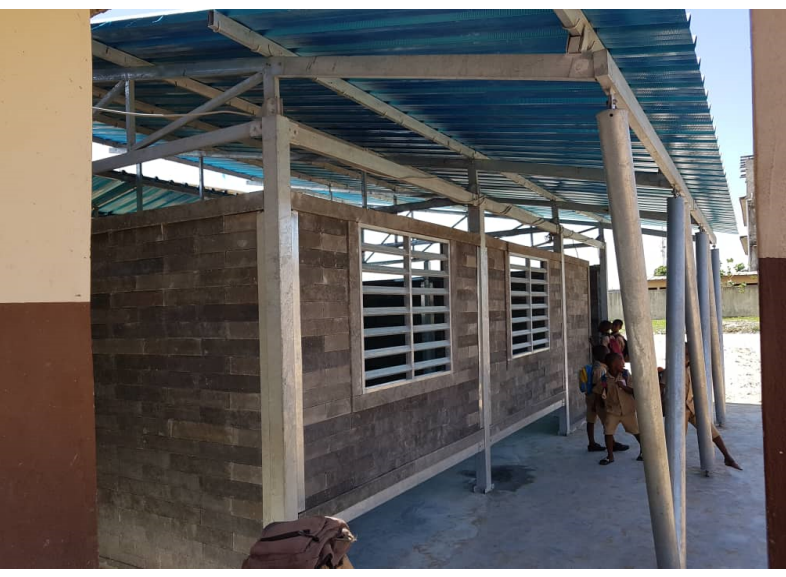

Fig. 10. The school in Colombia, $\mathrm{http}: / /$ conceptosplasticos.com/

Recycled materials constructions are high durability, resistance to chipping, and low-cost. Therefore, we can use them in detention facilities to resist walls deformation for prevention prisoners from escaping. Sustainable and diverse materials based on recycling materials can be a major component in the industrial production of low-cost pavement elements, as well as aesthetically appealing elements of improvement (Fig. 11).

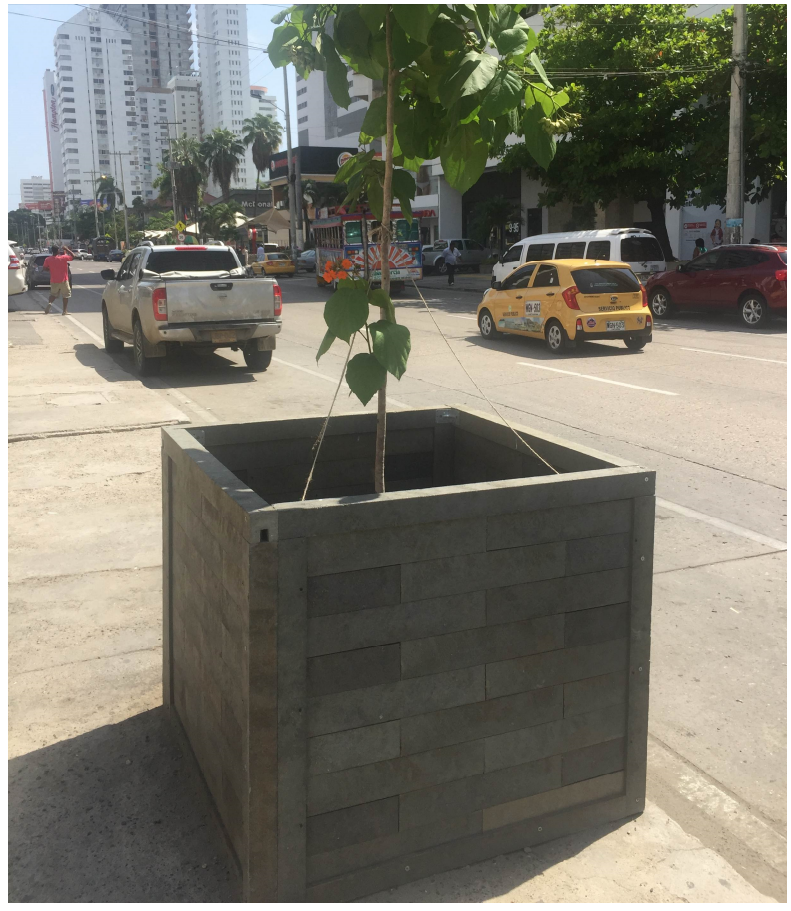

Fig. 11. Capacity for the plant, http://conceptosplasticos.com/

It is likely that in the further development of recycling technologies for polymeric materials will make it possible to manufacture a wide range of available construction products that will have high physical and mechanical qualities and a variety of aesthetic properties. The use of such architectural and construction products will expand the arsenal of the humanization of the urban environment. For example, new public spaces in densely populated central areas of coastal historic cities and mobile, environmentally neutral visitor facilities in pristine natural landscapes can produce from floating modules from recycled materials [30]. In this way, the introduction of advanced resource recycling technologies will help to strengthen overall sustainable development trends.

\section{Conclusions}

The ideas of sustainable development, which has a long history, has always attracted the attention of architects and urbanists from the standpoint of creating a perfective architectural environment in cities and urban areas. Today, the formation of a full-fledged environment increasingly focused on its harmonization, which aimed at overcoming the existing urban chaos and maximizing the use of internal reserves and the potentials of an effective organization and self-organization of the urban environment at all levels, stages, and locations of its development. The study shows that the harmonization of urban planning, as a whole, its specific spatial and functional components, as well as individual types of buildings, despite their complex multi-vector nature, together constitute not yet fully realized potentials and reserves of sustainable.

Ways to improve the architectural environment are associated with the implementation of synergistic methods in the practice of urban planning. In cities, it is advisable to purposefully formulate systems of the architectural environment that correspond to people with different psychological characteristics. Ways to improve the architectural environment must also be associated with the enhancement of aesthetic qualities of penitentiary buildings and their thoughtful placement on the territory of the settlements, with the creation of multifunctional multilevel public spaces and with the expansion of the reuse of industrial products and materials. The humanistic focus of harmonization allows reconciles the goals and values of free urban communities and groups with temporarily restricted freedom. It contributes to forming the full-fledged architectural environment of cities with the attraction of new concepts and ideas for sustainable development, as well as innovative technologies of architectural and urban planning, taking into account the aesthetic preferences and artistic tastes of urban residents and their communities.

\section{References}

1. Report of the United Nations Conference on Human Settlements (HABITAT II, Istanbul, 3-14 June 1996), https://www.un.org/ruleoflaw/wpcontent/uploads/2015/10/istanbul-declaration.pdf. Accessed 20 Dec 2019

2. Transforming our World: the 2030 Agenda for Sustainable Development, A/RES/70/1 (United Nations, New York, 25-27 September 2015), https://sustainabledevelopment.un.org/content/docu ments $/ 21252030 \% 20$ Agenda\%20for\%20Sustainable \%20Development\%20web.pdf. Accessed 20 Dec 2019 
3. F. L. Wright, Ischezayushchiy gorod (The Disappearing City). (Strelka, Moscow, 2016)

4. C. A. Doxiadis, Ekistics: an Introduction to the Science of Human Settlements (Hutchinson, London, 1968)

5. K. Lynch, The Image of the City (The MIT Press, Cambridge, 1960)

6. N. M. Shebek, Harmonizatsiya planuvalnoho rozvytku mista (Harmonization of the Town Planning Development). (Osnova, Kyiv, 2008)

7. V. Timokhin, Arkhitektura miskoho rozvytku. 7 knyh $z$ teoriyi mistobuduvannya (The Architecture of the Town Development. 7 Books on the Theory of Urban Planning). (KNUCA, Kyiv, 2008)

8. A. Augustinavichute, Socion (Socion). (Chernaya belka, Moscow, 2008)

9. C. Alker, Chris Alker on the Architecture of ReSocialization (Nate Murphy, May 10, 2011), https://prisondesign.wordpress.com/2011/05/10/chri s-alker-on-the-architecture-of-re-socialization/.

Accessed 20 Dec 2019

10. Global Sustainable Development Report 2019: The Future is Now - Science for Achieving Sustainable Development (UN, New York, 2019), https://sustainabledevelopment.un.org/content/docu ments/24797GSDR_report_2019.pdf. Accessed 20 Dec 2019

11. I. Spens (ed.), Architecture of Incarceretion (Academy editions, London, 1994)

12. P. Wood, State to push forward with $\$ 27$ million demolition of Baltimore jail - while saving some historic buildings (Baltimore Sun, Oct. 02, 2019), https://www.baltimoresun.com/politics/bs-md-polcity-jail-demo-20191002-

prhkw7odwrepvmb4zkt4uxx7ka-story.html.

Accessed 20 Dec 2019

13. C. Morris, Metropolitan Correctional Center. (Chicago Modern, March 19, 2012), https://chicagomodern.wordpress.com/2012/03/19/m etropolitan-correctional-center/. Accessed 18 Dec 2019

14. J. Jacobs, The Death and Life of Great American Cities (Vintage, New York, 1992)

15. E. Zaykova, Formation methods of hybrid urban spaces in the historic city center, E3S Web of $\begin{array}{llll}\text { Conferences } & 97, & 01031 & \text { (2019). }\end{array}$ doi:10.1051/e3sconf/20199701031

16. D. Stankovic, M. Tanic, A. Cvetanovic, The impact of intelligent systems on architectural aesthetics, E3S Web Conferences 110, 01044 (2019). doi:10.1051/e3sconf /201911001044

17. M. Argyriades, Metropol Parasol. The World's Largest Wooden Structure (Architecture, 28 APRIL 2011), https://www.yatzer.com/Metropol-ParasolThe-World-s-Largest-Wooden-Structure-JMAYER-H-Architects. Accessed 20 Dec 2019

18. R. Stott, Paris' Grande Arche to get $€ 200$ million Revamp (ArchDaily, August 06, 2014), https://www.archdaily.com/534994/paris-grandearche-to-get-eu200-million-revamp. Accessed 19 Dec 2019

19. A. Khitrov, How it is done. Building materials from plastic waste (Newslab.ru, 07.06.2016), http://newslab.ru/article/719194. Accessed 20 Dec 2019

20. Print Your City - Amsterdam (The New Raw, 2016), https://thenewraw.org/Print-Your-CityAmsterdam. Accessed 20 Dec 2019

21. Global Environment Outlook 6 (UN Environment, 04 March 2019),

https://www.unenvironment.org/resources/globalenvironment-outlook-6. Accessed 20 Dec 2019

22. Stan zabrudnennya pryrodnoho seredovyshcha na terytoriyi Ukrayiny (State of environmental pollution in the territory of Ukraine). (Central Geophysical Observatory named after B. Sreznevsky, 2019), http://cgosreznevskyi.kiev.ua/index.php?lang=en\&fn=u_zabr ud\&f=ukraine. Accessed 21 Dec 2019

23. GalPET, Flakes \& Pellets (2019), http://www.galpet.com.ua/syire-pokupaemprodaem. Accessed 21 Dec 2019

24. ZPHP "Region-2001", Recycling of Secondary Waste (2019), http://asphalt-beton-cementukraine.com/services/recycling-of-secondary-waste. Accessed 21 Dec 2019

25. Kyyivrada protyahla rishennya pro znyshchennya zavodu "Kyyivmiskvtorresursy" (The Kyiv city council has extended the decision to destroy the plant "Kyivmisktorresources"). (Ukrainian Pravda, Kyiv, 20.12.2016)

https://kiev.pravda.com.ua/news/58591fdb94c80/. Accessed 21 Dec 2019

26. ByFusion, ByBlock - build a better future (2019), https://www.byfusion.com/byblock/. Accessed 20 Dec 2019

27. J. Thorneycroft, J. Orr, P. Savoikar, R.J. Ball, Performance of structural concrete with recycled plastic waste as a partial replacement for sand. Constr. Build. Mater. 161, 63-69 (2018). doi:10.1016/j.conbuildmat.2017.11.127

28. J. Astbury, Lendager Group uses recycled materials to build 20 townhouses in Copenhagen (Dezeen, 16 April 2019),

https://www.dezeen.com/2019/04/16/upcyclestudios-townhouses-lendager-group-copenhagenrecycled-materials/. Accessed 20 Dec 2019

29. Conceptos Plasticos, Conoce nuestros productos (2019), http://conceptosplasticos.com/. Accessed 20 Dec 2019

30. N. Shebek, O. Olkhovets, Progressive technologies in design of town planning and landscape recreational objects made of floating modular elements. Underwater Technologies 09, 47-55 (2019). doi:10.31493/uwt1909.1901 